\title{
A Parsimonious Statistical Design and Breeding Procedure for Evaluating and Selecting Desirable Characteristics Over Environments
}

by

Walter T. Federer and Brian T. Scully ${ }^{1}$

BU-960-MA ${ }^{2}$

September 1992

\begin{abstract}
$\underline{\text { ABSTRACT }}$
The concept of stability as described in the literature does not meet all desirable criteria required by growers of cultivars. Various types of possible responses are discussed and these are divided into those desirable from a grower's viewpoint and those not. Measures of stability appearing in the literature are based on variances, linear regression slopes, and/or deviations from regression. The most desirable response type would be denoted as unstable by current concepts of stability. It is shown how to simulate environments which exceed the ranges found in practice. A statistical design is described which is the height of parsimony and has the advantage that the conditions varied are known. The experimental results can then be interpreted in light of the known conditions. The design is optimally cost effective in terms of funds, material, and personnel. A breeding procedure is presented for such characteristics as desired response, stability under current definitions, tolerance (to pests, cold, drought, etc.), protein, quality, fiber, etc.
\end{abstract}

\footnotetext{
${ }_{1}^{1}$ Liberty Hyde Bailey Professor Emeritus, Biometrics Unit, Dept. of Plant Breeding and Biometry, Cornell University, Ithaca, NY 14853; Assistant Professor of Vegetable Crops, IFAS, University of Florida, Everglades Research Center, Belle Glade, FL 33430.

${ }^{2}$ In the Technical Report Series of the Biometrics Unit, Cornell University, Ithaca, NY 14853.
} 


\section{$\underline{\text { Introduction }}$}

The stability of crop production, i.e., relatively constant annual yield of a crop grown by a farmer, is one of the most important issues facing world agriculture and food production; in some cases, stability is equally as important as yield itself. Stability is influenced by a cultivar's genetics, the environment in which it is grown, and the cropping system used in the environment. Across a diversity of these three factors, growers, marketers, consumers, and policy makers are confronted with the problem of dependability and predictability of food supply.

In an intensive cropping system such as vegetable production, growers stagger planting dates across the season in hopes of timing harvest for a given market. These growers know that correct (market) timing is commonly more profitable than high yield, and they need cultivars that are predictable across planting dates. "Good years" often bring record yields, but are often accompanied by lower prices. In "bad years" the reverse is true. For these growers, instability of yield results in market and price instability, which adversely affect the farm economy. In intensive cropping systems, commonly practiced in developing countries, stability is of paramount importance if growers are to feed family and community. In these countries, intercropping is a frequent system of choice because it ensures more production stability and more diversity of food for diet (Francis, 1981; Federer, 1993).

From the literature, it appears that the concept and definition of stability needs considerably more discussion and quantification (Lin et al., 1986; Verma et al., 1978). We shall attempt to make our use of this concept more consistent with the objectives of the grower rather than a statistical criterion. It will be necessary to study and consider various types of possible responses for cultivars grown in environments which range from poor to optimal. The range of environments encountered in practice should be included in the range of environments being considered in experiments studying the concept of stability. It will also be necessary to precisely define what is meant by poor and optimal environments. To us, there is considerable vagueness and imprecision attached to all of the above as they appear in the literature.

The purpose of this investigation is to explore and review the concept of stability, environment, and how they interact and affect a cultivar's response in terms of yield or any other quantitative 
trait. The second objective is to develop a parsimonious statistical design which allows estimation of stability, of response parameters, and a grower's desired response function of yield over changing environments. Our third purpose is to present a framework for the selection and breeding of a desired response function within the context of parsimonious statistical design. Finally, we discuss a set of breeding investigations where this methodology could be integrated into the experimental procedures.

\section{Environments}

It would appear that most experimenters consider an "environment" to be a single trial at a single locality and in a single year. They then attempt to obtain a range of environments by selecting "a random sample" of locations and years. It is not clear how or if this can be accomplished, especially when the population of years or sites is not defined. Others decide to select locations which cover the range of "conditions" to be met in practice. The "conditions" are not defined except to say that these are supposed to be the conditions encountered by farmers who grow these cultivars. If the factors creating the environments or conditions are not defined precisely, how can one cover a range of such "conditions or environments"? The thinking of the first author has been greatly influenced by his contacts with LeRoy Powers, deceased sugar beet and tomato breeder, D. W. (Scotty) Robertson, deceased barley breeder, B. N. Okigbo, IITA, Ibadan, Nigeria, and several others. These individuals expounded the idea that the researcher should know precisely what conditions he wished to use and to create these conditions in an experiment. They contended that cultivar by location (genotype by environment to many researchers) interaction was not of much use unless one knew the elements making environments different. As one forage crop specialist, Jack L. Harlan, put it, "One can make any forage cultivar come out on top simply by changing the dates of cutting." This statement shows the necessity of precisely defining the objectives of the grower of these cultivars. Note that a particular breeder's objectives are rather immaterial unless the needs of the growers are met.

Now, what are some of the factors causing poor, fair, or optimal growing conditions or environments? Certainly, the amount of water available for a crop at critical times in the growing 
season is a prime factor. A second one is soil type and fertility. A third would be the number and kind of insects present as well as the type and amount of disease. Another important factor would be biological, not necessarily calendar, date of planting and harvest. Other factors could be amount of sunshine, fog, wind, elevation, etc. Regardless of the factors making environments different, it is necessary to precisely define what is meant by poor, fair, and good environments with respect to the characteristic being measured. Once the factors affecting variation in environments and their frequency in the population is determined, experiments can then be conducted which include this range of variation for most of these factors. Breeders do this to some extent when they make their selections under low fertility and high fertility conditions, when they make their bean selections under intercropping with maize, when selections are made under low and high disease or insect infestations, when selections are made under drought and non-drought conditions, etc. Rather than considering changing environments for only one or two factors, selections should be made considering all factors, or at least the major ones, affecting cultivar response grown under various known environmental conditions.

\section{Cultivar Responses}

Responses of cultivars to varying environments can be completely different. There is no set pattern or form of response as this depends upon the genotype. Some possible responses of cultivars to changing environments is depicted in Figure 1. Type $S_{1}$ response would be for a low yielding cultivar which did not make use of the better environmental conditions. Note that the extreme case of a type $S_{1}$ response is where a cultivar has zero yield under any environment.

The response $S_{2}$ is for a cultivar that performs well (compared to $S_{1}$ ) at poor environments and takes some advantage of bettering environments in a linear manner. This cultivar would have a small slope when its yield $\mathrm{Y}$ is plotted against the environmental index $\mathrm{X}$ (often taken to be the yield of a large number of cultivars at a specified site and year). Likewise, its variance in yield over all environments is small. $\mathrm{S}_{1}$, however, has zero slope and zero variance, which under several proposed stability measures (see Lin et al., 1986) would be optimal. $\mathrm{S}_{2}$ would also rate high in stability under these measures. However, $S_{2}$ would be much preferred to $S_{1}$ from a grower's viewpoint and needs. 


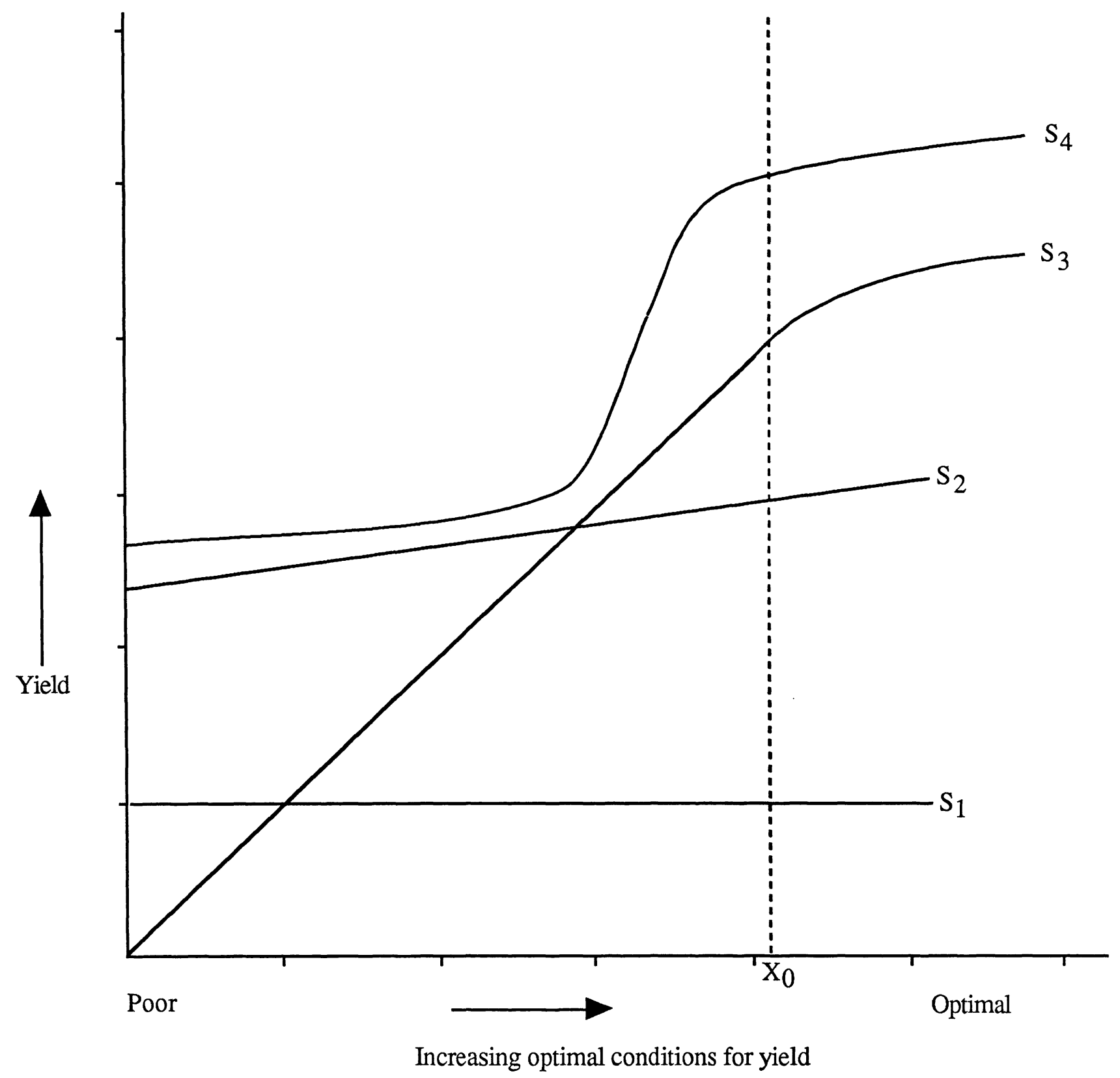

Figure 1. Cultivar responses to changing environments. 
$\mathrm{S}_{3}$ is a cultivar that responds poorly to poor environments but responds in a linear fashion to increasing environmental indices up to some point $X_{0}$. After $X_{0}$, the $S_{3}$ response tends to change with $\mathrm{X}$ in a curvilinear manner and reaches some asymptotic level. The high slope and high variance of $\mathrm{S}_{3}$ would make it an "unstable" cultivar under current definitions in the literature. In good environments, $S_{3}$ would be superior to $S_{2}$ from a grower's point of view and if only good environments were to be considered, $S_{3}$ would be the selected cultivar. Likewise, if poor environments were encountered infrequently, $S_{3}$ might still be selected over the "stable" cultivar $S_{2}$. This would depend upon whether or not the grower could afford to have the low yields of $S_{3}$ in poor environments on an infrequent basis.

The $\mathrm{S}_{4}$ type of response would be the desirable one for most growers. $\mathrm{S}_{4}$ gives relatively high yields in poor environments and is able to take advantage of increasingly optimal environments. Although this cultivar response would have a relatively high slope and variance and would be classified as unstable, it would be the desired response that many growers would want. This is in agreement with Verma et al. (1978) and Pooni and Jinks (1980), where they suggest a segmented regression approach rather than the sigmoid response curve given in Figure 1.

There are various types of responses of the form given by $\mathrm{S}_{4}$. Some of these are given in Figure 2. It is assumed that to have a desirable form of response there is some minimum level of response at poor conditions which can be tolerated, i.e., $\mathrm{Y}_{0}$. This level for subsistence farmers would be the minimum yield required for the family's survival. All acceptable cultivars must be above this level in all environments to be encountered. Response type $D_{1}$ would be for a cultivar that only responds well to quite good environments. Response $D_{2}$ is similar to $S_{3}$ in Figure 1 . Cultivars with response $D_{3}$ respond in a linear manner to increasing environmental indices up to some point $\mathrm{X}_{0}$. Cultivars which respond to increasingly optimal conditions very quickly and then level off are of type $\mathrm{D}_{4}$. This type of response would certainly be desired over all the other types of responses if the goal were to maximize yields over all environments. Cultivars having the $\mathrm{D}_{2}$ response would be those having a type of threshold value of the environment before they could take advantage of a more favorable environment. For each cross, a breeder could evaluate the various kinds of responses to determine which of the responses $D_{1}$ to $D_{4}$ are encountered, how frequently, and from what type of parents. 


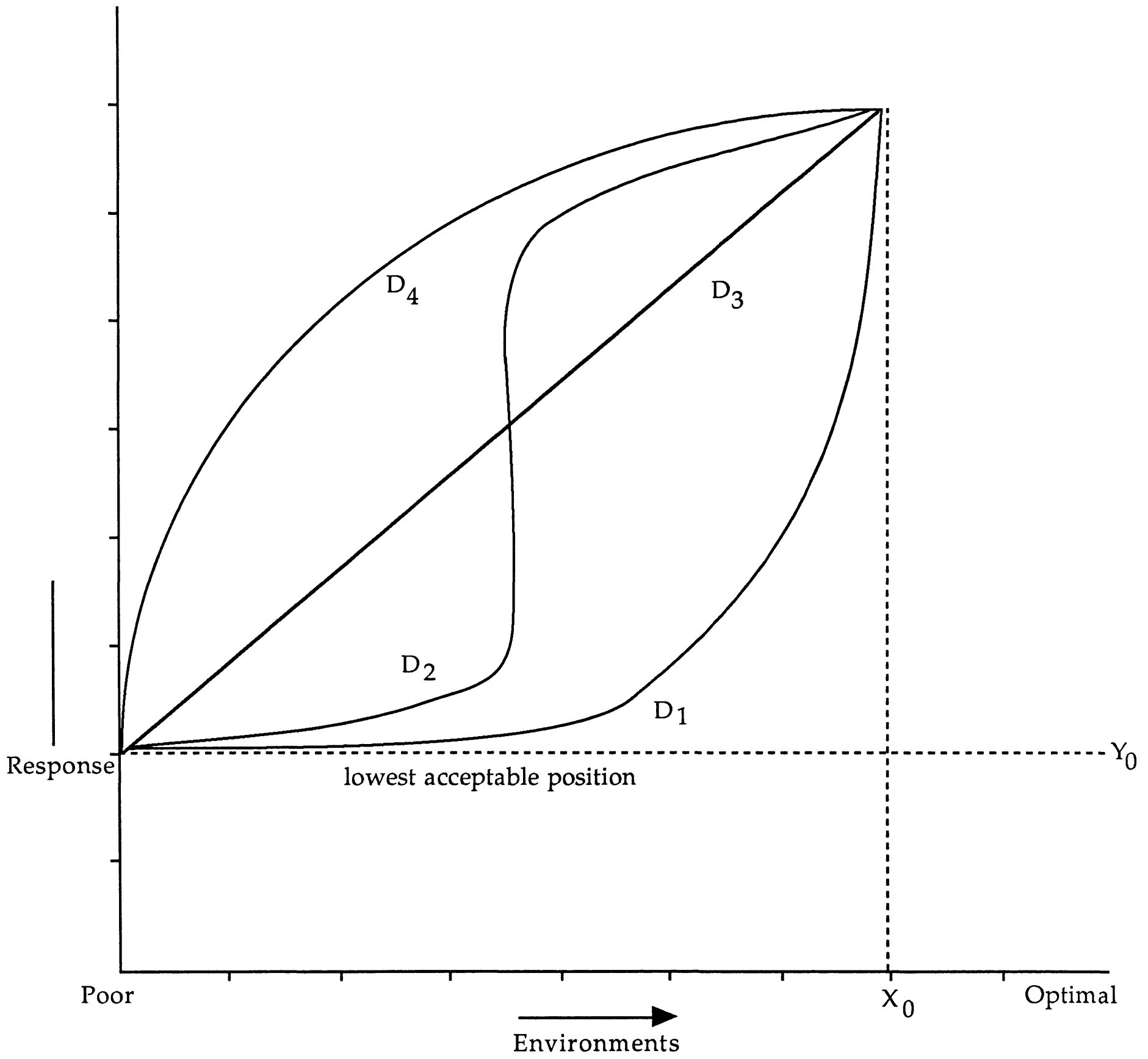

Figure 2. Types of desirable responses for cultivars. 


\section{A Parsimonious Statistical Design}

The present situation for evaluating stability, genotype by environment interaction, and evaluating cultivars for a target region is to conduct experiments at a number of locations (sites) and over a period of years. The cost of finding sites, travel, food, and lodging can make such types of experiments costly. Obtaining a large number of sites, say 100 , could be prohibitively costly. An alternative is to "select" sites which contain the range of conditions to be encountered by growers in the target region. Although this may appear reasonable, probably only the apparently obvious conditions could be selected. This may also be a costly procedure. It should be realized that whatever "sample" of sites is selected, there is the possibility that only a very small range of environments will be encountered. Hence, any regression curves based on this limited range of environments would be unreliable and could even be misleading. Another point to consider is that for some cultivars, plant material in the early stages may be very limited, e.g., sugarcane. Because of lack of plant material, an experiment at several sites may be impossible.

The question is, can these problems be resolved? The answer is definitely in the affirmative. To do this we suggest the following. Select factors which are the major causes of environmental differences such as, e.g.,

Category 1

water (rainfall) level

fertilizer level

biological planting and harvesting dates

disease and insect level

weed level

crop density

spatial arrangement

drought periods

soil salt.

\section{Category 2}

soil type

elevation or altitude

temperature

type of farming

\section{$\vdots$}

The factors in Category 1 could be varied from low to high within a single experimental unit (a cultivar or treatment) while the factors in Category 2 would have to be whole plots at selected sites. Some factors in Category 1, e.g., disease and insect level, may need to be set up as whole plots. For those factors which can be varied within a single experimental unit, some such arrangement as in Figure 3 might be used for a whole plot. Note that whole plots need not be adjacent but could be in 
different parts of a field or even in different fields. Also, there could be replication within a whole plot, e.g., elevations.

A particular whole plot is given in Figure 3 for $\mathrm{v}$ cultivars as the split plots. The split plot experimental units should be long and narrow and should be arranged such that competition between the split plot experimental units (speus) is eliminated. This can be done by increasing the distance between speus and increasing plant density within speus. This technique can be used to keep density per hectare constant while eliminating competition.

As depicted in Figure 3, within each split plot the factor(s) to be varied, e.g., water plus fertilizer, would be varied from insufficient water plus fertilizer to optimal water plus fertilizer. This would be done for each split plot in the same manner. The split plots should be as alike as possible. The range of levels of the varied factor(s) should exceed any that would be encountered by a grower of the crop. Providing a wide range of conditions improves the response function estimates. Note that the entire range of environments would be included in each speu and that this should be wider than what would be encountered by selecting a "sample" of sites.

1 Whole Plot

\begin{tabular}{|c|c|c|c|c|c|c|c|}
\hline $\begin{array}{c}\text { Poor } \\
\text { Conditions }\end{array}$ & $\begin{array}{l}\mathrm{x} \times \mathrm{x} \\
\mathrm{x} \times \mathrm{x} \\
\mathrm{x} \times \mathrm{x} \\
\mathrm{x} \times \mathrm{x} \\
\mathrm{x} \times \mathrm{x} \\
\mathrm{x} \times \mathrm{x} \\
\mathrm{x} \times \mathrm{x} \\
\mathrm{x} \times \mathrm{x} \\
\mathrm{x} \times \mathrm{x} \\
\mathrm{x} \times \mathrm{x} \\
\mathrm{x} \times \mathrm{x} \\
\mathrm{x} \times \mathrm{x} \\
\mathrm{x} \times \mathrm{x} \\
\mathrm{x} \times \mathrm{x} \\
\mathrm{x} \times \mathrm{x} \\
\mathrm{x} \times \mathrm{x} \\
\mathrm{x} \times \mathrm{x} \\
\mathrm{x} \times \mathrm{x} \\
\mathrm{x} \times \mathrm{x} \\
\mathrm{x} \times \mathrm{x} \\
\mathrm{x} \times \mathrm{x} \\
\mathrm{x} \times \mathrm{x}\end{array}$ & $\begin{array}{l}\mathrm{x} \times \mathrm{X} \\
\mathrm{x} \times \mathrm{x} \\
\mathrm{x} \times \mathrm{x} \\
\mathrm{x} \times \mathrm{x} \\
\mathrm{x} \times \mathrm{x} \\
\mathrm{x} \times \mathrm{x} \\
\mathrm{x} \times \mathrm{x} \\
\mathrm{x} \times \mathrm{x} \\
\mathrm{x} \times \mathrm{x} \\
\mathrm{x} \times \mathrm{x} \\
\mathrm{x} \times \mathrm{x} \\
\mathrm{x} \times \mathrm{x} \\
\mathrm{x} \times \mathrm{x} \\
\mathrm{x} \times \mathrm{x} \\
\mathrm{x} \times \mathrm{x} \\
\mathrm{x} \times \mathrm{x} \\
\mathrm{x} \times \mathrm{x} \\
\mathrm{x} \times \mathrm{x} \\
\mathrm{x} \times \mathrm{x} \\
\mathrm{x} \times \mathrm{x} \\
\mathrm{x} \times \mathrm{x} \\
\mathrm{x} \times \mathrm{x}\end{array}$ & $\begin{array}{l}\mathrm{x} \times \mathrm{x} \\
\mathrm{x} \times \mathrm{x} \\
\mathrm{x} \times \mathrm{x} \\
\mathrm{x} \times \mathrm{x} \\
\mathrm{x} \times \mathrm{x} \\
\mathrm{x} \times \mathrm{x} \\
\mathrm{x} \times \mathrm{x} \\
\mathrm{x} \times \mathrm{x} \\
\mathrm{x} \times \mathrm{x} \\
\mathrm{x} \times \mathrm{x} \\
\mathrm{x} \times \mathrm{x} \\
\mathrm{x} \times \mathrm{x} \\
\mathrm{x} \times \mathrm{x} \\
\mathrm{x} \times \mathrm{x} \\
\mathrm{x} \times \mathrm{x} \\
\mathrm{x} \times \mathrm{x} \\
\mathrm{x} \times \mathrm{x} \\
\mathrm{x} \times \mathrm{x} \\
\mathrm{x} \times \mathrm{x} \\
\mathrm{x} \times \mathrm{x} \\
\mathrm{x} \times \mathrm{x} \\
\mathrm{x} \times \mathrm{x}\end{array}$ & $\begin{array}{l}\mathrm{x} \times \mathrm{x} \\
\mathrm{x} \times \mathrm{x} \\
\mathrm{x} \times \mathrm{x} \\
\mathrm{x} \times \mathrm{x} \\
\mathrm{x} \times \mathrm{x} \\
\mathrm{x} \times \mathrm{x} \\
\mathrm{x} \times \mathrm{x} \\
\mathrm{x} \times \mathrm{x} \\
\mathrm{x} \times \mathrm{x} \\
\mathrm{x} \times \mathrm{x} \\
\mathrm{x} \times \mathrm{x} \\
\mathrm{x} \times \mathrm{x} \\
\mathrm{x} \times \mathrm{x} \\
\mathrm{x} \times \mathrm{x} \\
\mathrm{x} \times \mathrm{x} \\
\mathrm{x} \times \mathrm{x} \\
\mathrm{x} \times \mathrm{x} \\
\mathrm{x} \times \mathrm{x} \\
\mathrm{x} \times \mathrm{x} \\
\mathrm{x} \times \mathrm{x} \\
\mathrm{x} \times \mathrm{x} \\
\mathrm{x} \times \mathrm{x}\end{array}$ & $\begin{array}{l}\mathrm{x} \times \mathrm{x} \\
\mathrm{x} \times \mathrm{x} \\
\mathrm{x} \times \mathrm{x} \\
\mathrm{x} \times \mathrm{x} \\
\mathrm{x} \times \mathrm{x} \\
\mathrm{x} \times \mathrm{x} \\
\mathrm{x} \times \mathrm{x} \\
\mathrm{x} \times \mathrm{x} \\
\mathrm{x} \times \mathrm{x} \\
\mathrm{x} \times \mathrm{x} \\
\mathrm{x} \times \mathrm{x} \\
\mathrm{x} \times \mathrm{x} \\
\mathrm{x} \times \mathrm{x} \\
\mathrm{x} \times \mathrm{x} \\
\mathrm{x} \times \mathrm{x} \\
\mathrm{x} \times \mathrm{x} \\
\mathrm{x} \times \mathrm{x} \\
\mathrm{x} \times \mathrm{x} \\
\mathrm{x} \times \mathrm{x} \\
\mathrm{x} \times \mathrm{x} \\
\mathrm{x} \times \mathrm{x} \\
\mathrm{x} \times \mathrm{x}\end{array}$ & $\begin{array}{l}\mathrm{x} \times \mathrm{x} \\
\mathrm{x} \times \mathrm{x} \\
\mathrm{x} \times \mathrm{x} \\
\mathrm{x} \times \mathrm{x} \\
\mathrm{x} \times \mathrm{x} \\
\mathrm{x} \times \mathrm{x} \\
\mathrm{x} \times \mathrm{x} \\
\mathrm{x} \times \mathrm{x} \\
\mathrm{x} \times \mathrm{x} \\
\mathrm{x} \times \mathrm{x} \\
\mathrm{x} \times \mathrm{x} \\
\mathrm{x} \times \mathrm{x} \\
\mathrm{x} \times \mathrm{x} \\
\mathrm{x} \times \mathrm{x} \\
\mathrm{x} \times \mathrm{x} \\
\mathrm{x} \times \mathrm{x} \\
\mathrm{x} \times \mathrm{x} \\
\mathrm{x} \times \mathrm{x} \\
\mathrm{x} \times \mathrm{x} \\
\mathrm{x} \times \mathrm{x} \\
\mathrm{x} \times \mathrm{x} \\
\mathrm{x} \times \mathrm{x}\end{array}$ & 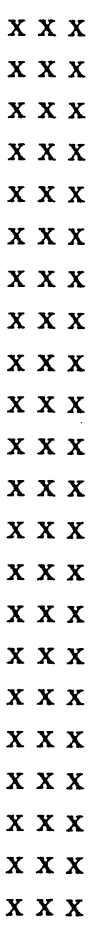 \\
\hline
\end{tabular}

Figure 3. Experimental units with a range of environments in each speu. 
To incorporate conditions for two factors, or two sets of factors, in a split plot experimental unit, the two factors could be varied as in the experimental unit depicted in Figure 4. Here plant density is varied from low to high and planting date from early to late. Data taken on individual plants or on individual subunits may be used to fit a response function of yields again known levels of the two factors varied. Combining the ideas of Figure 4 with those of Mead and Riley (1981, Figure 5), it may be possible to add another variable like spatial arrangement to Figure 4. Other schemes are possible. The type will depend upon the variables, the goals, and the creativity of the experimenter.

Planting date

\begin{tabular}{|c|c|c|c|c|c|c|c|c|c|c|c|c|c|c|c|c|c|c|c|c|}
\hline \multirow{2}{*}{$\begin{array}{c}\text { Density } \\
\text { low }\end{array}$} & \multicolumn{9}{|c|}{ Early } & \multicolumn{10}{|c|}{ Optimal } & \multirow{2}{*}{$\mathrm{x}$} \\
\hline & $\mathbf{x}$ & $\mathbf{x}$ & $\mathbf{x}$ & $\mathbf{x}$ & $\mathbf{x}$ & $\mathbf{x}$ & $\mathbf{x}$ & $\mathbf{x}$ & $\mathbf{x}$ & $\mathbf{x}$ & $\mathbf{x}$ & $\mathbf{x}$ & $\mathbf{x}$ & $\mathbf{x}$ & $\mathbf{x}$ & $\mathbf{x}$ & $\mathbf{x}$ & $\mathbf{x}$ & $\mathbf{x}$ & \\
\hline & $\mathbf{x}$ & $\mathrm{x}$ & $\mathbf{x}$ & $\mathbf{x}$ & $\mathbf{x}$ & $\mathrm{x}$ & $\mathrm{x}$ & $\mathrm{x}$ & $\mathbf{x}$ & $\mathbf{x}$ & $\mathbf{x}$ & $\mathbf{x}$ & $\mathrm{x}$ & $\mathbf{x}$ & $\mathrm{x}$ & $\mathrm{x}$ & $\mathrm{x}$ & $\mathrm{x}$ & $\mathrm{x}$ & $\mathbf{x}$ \\
\hline & $\mathbf{x}$ & $\mathrm{x}$ & $\mathrm{x}$ & $\mathbf{x}$ & $\mathbf{x}$ & $\mathbf{x}$ & $\mathbf{x}$ & $\mathbf{x}$ & $\mathbf{x}$ & $\mathbf{x}$ & $\mathbf{x}$ & $\mathbf{x}$ & $\mathbf{x}$ & $\mathbf{x}$ & $\mathbf{x}$ & $\mathrm{x}$ & $\mathbf{x}$ & $\mathrm{x}$ & $\mathrm{x}$ & $\mathbf{x}$ \\
\hline & $\mathbf{x}$ & $\mathrm{x}$ & $\mathbf{x}$ & $\mathbf{x}$ & $\mathbf{x}$ & $\mathbf{x}$ & $\mathrm{x}$ & $\mathbf{x}$ & $\mathbf{x}$ & $\mathbf{x}$ & $\mathbf{x}$ & $\mathbf{x}$ & $\mathbf{x}$ & $\mathbf{x}$ & $\mathbf{x}$ & $\mathrm{x}$ & $\mathrm{x}$ & $\mathbf{x}$ & $\mathrm{x}$ & $\mathbf{x}$ \\
\hline & $\mathbf{x}$ & $\mathbf{x}$ & $\mathrm{x}$ & $\mathbf{x}$ & $\mathbf{x}$ & $\mathbf{x}$ & $\mathbf{x}$ & $\mathbf{x}$ & $\mathbf{x}$ & $\mathbf{x}$ & $\mathbf{x}$ & $\mathbf{x}$ & $\mathbf{x}$ & $\mathbf{x}$ & $\mathbf{x}$ & $\mathbf{x}$ & $\mathrm{x}$ & $\mathbf{x}$ & $\mathrm{x}$ & $\mathbf{x}$ \\
\hline & $\mathbf{x}$ & $\mathbf{x}$ & $\mathbf{x}$ & $\mathbf{x}$ & $\mathbf{x}$ & $\mathbf{x}$ & $\mathrm{x}$ & $\mathbf{x}$ & $\mathbf{x}$ & $\mathbf{x}$ & $\mathbf{x}$ & $\mathbf{x}$ & $\mathbf{x}$ & $\mathbf{x}$ & $\mathbf{x}$ & $\mathbf{x}$ & $\mathbf{x}$ & $\mathbf{x}$ & $\mathbf{x}$ & $\mathbf{x}$ \\
\hline & $\mathbf{x}$ & $\mathbf{x}$ & $\mathbf{x}$ & $\mathbf{x}$ & $\mathbf{x}$ & $\mathbf{x}$ & $\mathrm{x}$ & $\mathbf{x}$ & $\mathbf{x}$ & $\mathbf{x}$ & $\mathbf{x}$ & $\mathbf{x}$ & $\mathbf{x}$ & $\mathbf{x}$ & $\mathbf{x}$ & $\mathbf{x}$ & $\mathbf{x}$ & $\mathbf{x}$ & $\mathrm{x}$ & $\mathbf{x}$ \\
\hline & $\mathbf{x}$ & $\mathbf{x}$ & $\mathbf{x}$ & $\mathbf{x}$ & $\mathbf{x}$ & $\mathbf{x}$ & $\mathbf{x}$ & $\mathbf{x}$ & $\mathbf{x}$ & $\mathbf{x}$ & $\mathbf{x}$ & $\mathbf{x}$ & $\mathbf{x}$ & $\mathbf{x}$ & $\mathbf{x}$ & $\mathbf{x}$ & $\mathbf{x}$ & $\mathbf{x}$ & $\mathbf{x}$ & $\mathbf{x}$ \\
\hline & $\mathbf{x}$ & $\mathbf{x}$ & $\mathrm{x}$ & $\mathbf{x}$ & $\mathbf{x}$ & $\mathbf{x}$ & $\mathbf{x}$ & $\mathbf{x}$ & $\mathbf{x}$ & $\mathbf{x}$ & $\mathbf{x}$ & $\mathbf{x}$ & $\mathbf{x}$ & $\mathbf{x}$ & $\mathbf{x}$ & $\mathbf{x}$ & $\mathbf{x}$ & $\mathbf{x}$ & $\mathbf{x}$ & $\mathbf{x}$ \\
\hline & $\mathbf{x}$ & $\mathbf{x}$ & $\mathrm{x}$ & $\mathrm{x}$ & $\mathbf{x}$ & $\mathbf{x}$ & $\mathbf{x}$ & $\mathbf{x}$ & $\mathbf{x}$ & $\mathbf{x}$ & $\mathbf{x}$ & $\mathbf{x}$ & $\mathbf{x}$ & $\mathrm{x}$ & $\mathbf{x}$ & $\mathbf{x}$ & $\mathbf{x}$ & $\mathbf{x}$ & $\mathbf{x}$ & $\mathbf{x}$ \\
\hline & $\mathbf{x}$ & $\mathbf{x}$ & $\mathbf{x}$ & $x$ & $\mathbf{x}$ & $\mathbf{x}$ & $\mathrm{x}$ & $\mathbf{x}$ & $\mathbf{x}$ & $\mathbf{x}$ & $\mathbf{x}$ & $\mathbf{x}$ & $\mathbf{x}$ & $\mathrm{x}$ & $\mathbf{x}$ & $\mathrm{x}$ & $\mathbf{x}$ & $\mathrm{x}$ & $\mathbf{x}$ & $\mathrm{x}$ \\
\hline & $\mathbf{x}$ & $\mathbf{x}$ & $\mathrm{x}$ & $\mathrm{x}$ & $\mathbf{x}$ & $\mathbf{x}$ & $\mathbf{x}$ & $\mathbf{x}$ & $\mathbf{x}$ & $\mathbf{x}$ & $\mathbf{x}$ & $\mathbf{x}$ & $\mathbf{x}$ & $\mathbf{x}$ & $\mathrm{x}$ & $\mathbf{x}$ & $\mathrm{x}$ & $\mathbf{x}$ & $\mathbf{x}$ & $\mathbf{x}$ \\
\hline & $\mathbf{x}$ & $\mathrm{x}$ & $\mathbf{x}$ & $\mathbf{x}$ & $\mathbf{x}$ & $\mathbf{x}$ & $\mathbf{x}$ & $x$ & $\mathbf{x}$ & $\mathbf{x}$ & $\mathrm{x}$ & $\mathbf{x}$ & $\mathbf{x}$ & $\mathbf{x}$ & $\mathbf{x}$ & $\mathbf{x}$ & $\mathbf{x}$ & $\mathbf{x}$ & $\mathbf{x}$ & $\mathbf{x}$ \\
\hline & $\mathbf{x}$ & $\mathbf{x}$ & $\mathrm{x}$ & $\mathrm{x}$ & $\mathbf{x}$ & $\mathbf{x}$ & $\mathbf{x}$ & $\mathbf{x}$ & $\mathbf{x}$ & $\mathbf{x}$ & $\mathrm{x}$ & $\mathbf{x}$ & $\mathbf{x}$ & $\mathbf{x}$ & $\mathbf{x}$ & $\mathbf{x}$ & $\mathrm{x}$ & $\mathbf{x}$ & $\mathbf{x}$ & $\mathbf{x}$ \\
\hline & $\mathbf{x}$ & $\mathrm{x}$ & $\mathbf{x}$ & $\mathbf{x}$ & $\mathbf{x}$ & $\mathbf{x}$ & $\mathbf{x}$ & $\mathbf{x}$ & $\mathbf{x}$ & $\mathbf{x}$ & $\mathbf{x}$ & $\mathbf{x}$ & $\mathbf{x}$ & $\mathbf{x}$ & $\mathbf{x}$ & $\mathbf{x}$ & $\mathrm{x}$ & $\mathrm{x}$ & $\mathbf{x}$ & $\mathrm{x}$ \\
\hline & $\mathbf{x}$ & $\mathbf{x}$ & $\mathrm{x}$ & $\mathbf{x}$ & $\mathrm{x}$ & $\mathbf{x}$ & $\mathrm{x}$ & $\mathbf{x}$ & $\mathbf{x}$ & $\mathbf{x}$ & $\mathbf{x}$ & $\mathbf{x}$ & $\mathbf{x}$ & $\mathbf{x}$ & $\mathbf{x}$ & $\mathbf{x}$ & $\mathbf{x}$ & $\mathrm{x}$ & $\mathrm{x}$ & $\mathbf{x}$ \\
\hline & $\mathbf{x}$ & $\mathbf{x}$ & $\mathbf{x}$ & $\mathbf{x}$ & $\mathbf{x}$ & $\mathbf{x}$ & $\mathrm{x}$ & $\mathbf{x}$ & $\mathbf{x}$ & $\mathbf{x}$ & $\mathbf{x}$ & $\mathbf{x}$ & $\mathbf{x}$ & $\mathbf{x}$ & $\mathrm{x}$ & $\mathbf{x}$ & $\mathrm{x}$ & $\mathrm{x}$ & $\mathbf{x}$ & $\mathbf{x}$ \\
\hline & $\mathbf{x}$ & $\mathbf{x}$ & $\mathbf{x}$ & $\mathbf{x}$ & $\mathrm{x}$ & $\mathbf{x}$ & $\mathbf{x}$ & $\mathbf{x}$ & $\mathbf{x}$ & $\mathbf{x}$ & $\mathbf{x}$ & $\mathbf{x}$ & $\mathbf{x}$ & $\mathbf{x}$ & $\mathbf{x}$ & $\mathbf{x}$ & $\mathbf{x}$ & $\mathbf{x}$ & $\mathbf{x}$ & $\mathbf{x}$ \\
\hline & $\mathbf{x}$ & $\mathbf{x}$ & $\mathrm{x}$ & $\mathbf{x}$ & $\mathbf{x}$ & $\mathbf{x}$ & $\mathbf{x}$ & $\mathbf{x}$ & $\mathbf{x}$ & $\mathbf{x}$ & $\mathrm{x}$ & $\mathbf{x}$ & $\mathbf{x}$ & $\mathbf{x}$ & $\mathbf{x}$ & $\mathbf{x}$ & $\mathbf{x}$ & $\mathbf{x}$ & $\mathbf{x}$ & $\mathbf{x}$ \\
\hline dense & $\mathbf{x}$ & $\mathrm{x}$ & $\mathrm{x}$ & $\mathrm{x}$ & $\mathrm{x}$ & $\mathbf{x}$ & $\mathbf{x}$ & $\mathbf{x}$ & $\mathbf{x}$ & $\mathbf{x}$ & $\mathrm{x}$ & $\mathbf{x}$ & $\mathbf{x}$ & $\mathrm{x}$ & $\mathbf{x}$ & $\mathbf{x}$ & $\mathbf{x}$ & $\mathrm{x}$ & $\mathbf{x}$ & $\mathbf{x}$ \\
\hline
\end{tabular}

Figure 4. Experimental unit for one cultivar and varying density and planting date.

If a third factor is introduced, then a plant like Figure 5 might be appropriate. The four rectangles could be a plan as in Figure 4, and the different rectangles could be four levels of another variable. Also, instead of a rectangle, a Nelder (1962) type fan could be placed in each of the four quadrants of a circle as pictured in Figure 5. Fertilizer level and date of planting could be the two variables for each quadrant. Then, the different quadrants could be different amounts of moisture applied. Alternatively, two variables as in Figure 4 could form the experimental unit; then for two or 


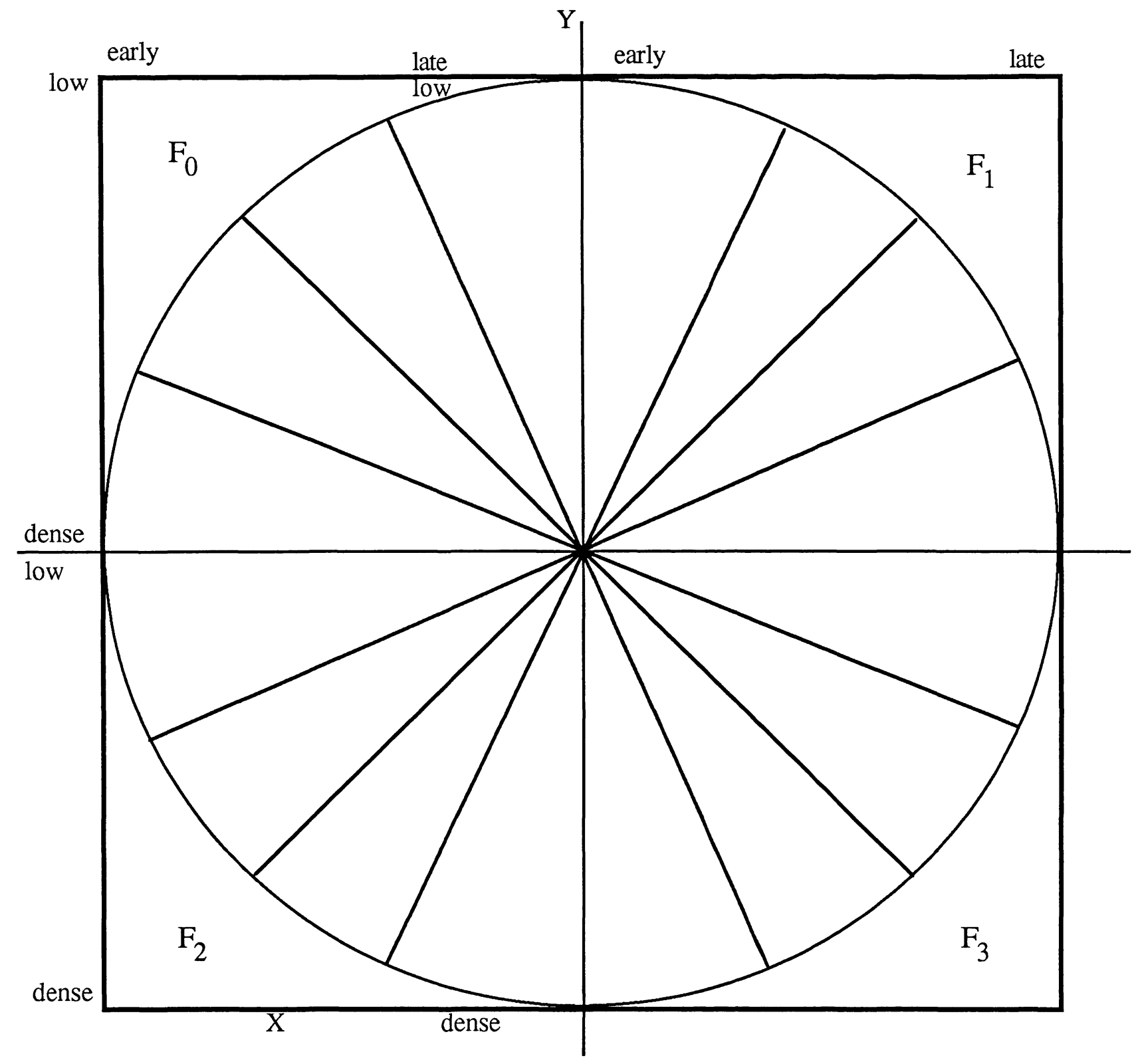

Figure 5. Experimental units for the three variables: density, time of planting, and four fertilizer levels $\left(\mathrm{F}_{0}, \ldots, \mathrm{F}_{3}\right)$. 
more other variables, a factorial arrangement (or a fractional replicate) could be used on the experimental units. These would be randomized as usual. If it were desired to study factors individually some sort of split-split plot, split-split-split plot, and/or split block arrangements would be appropriate.

Various experiment designs may be used. As an example, suppose that slope of land and elevation were two variables that needed consideration in evaluating treatment response for the area in question. Suppose further that planting dates of early, optimal, and late needed to be included, and also that water and fertilizer levels were to be varied as in Figure 4 . Then for the v treatments or genotypes under consideration, the slope types and elevations, either in a fractional or complete factorial, would form the whole plots. Replication of the whole plots may or may not be done. Also, replication of split plot treatments within each whole plot may or may not be used. The split-split plot treatments would appear in each split plot and each whole plot and when only one replicate of the whole experiment design was used, components of interaction sums of squares would be used to form an experimental error mean square. If replication of the whole plots were desired, this could be accomplished by using sites and/or years as blocks.

The measurements would be made by splitting each speu into $n$ subunits or the plants could be measured continuously through the speu. This would depend upon the method of varying the factor(s) through the speu. For each speu, a response function would be fitted to the data. The particular regression function fitted would be arbitrary until sufficient data have been collected to ascertain the types of response functions encountered in practice. These could then be used as the response functions. From the data presented by Verma et al. (1978), it would appear that a simple quadratic regression equation

$$
\mathrm{Y}_{i}=\text { response } \mathrm{i}=\alpha+\beta \mathrm{X}_{i}+\gamma \mathrm{X}_{i}^{2}
$$

would suffice in many situations. This is form $\mathrm{D}_{1}$ and $\mathrm{D}_{4}$ in Figure 2. Such a regression equation can only be regarded as an approximation to the true response function. For some situations, the approximation may recover all the needed information. Note that for responses of type $D_{2}$ and $S_{3}$, 
the approximation would be inappropriate and would not recover the information contained therein.

In lieu of information of the exact nature of cultivar responses to changing environments, it is suggested that the above quadratic regression equation be used as a first approximation. Then, a desirable or acceptable cultivar in Figure 2 would have the following characteristics:

1. The intercept $\alpha$ would be at or preferably above the minimum acceptable level $\mathrm{Y}_{0}$,

2. The linear regression slope $\beta$ should be positive and a maximum,

and

3. The quadratic coefficient $\gamma$ should be as large as possible negatively (response $D_{4}$ ). Even positive $\hat{\gamma}$ 's $\left(D_{1}\right)$ may be accepted depending upon the material and goals.

Thus, for each speu, an estimated intercept $\hat{\alpha}$, and estimated slope $\hat{\beta}$, and an estimated quadratic regression coefficient $\hat{\gamma}$, would be obtained. These would be the measurements to use in selecting cultivars either for parents in a breeding program or for growers.

The statistical design given above

i) minimizes cost, material, and other resources,

ii) covers a known range of environments,

iii) allows interpretation of responses over known conditions,

iv) assures that a range of environments is present in the experiment,

v) achieves the height of parsimony,

vi) is usable for a variety of investigations,

and

vii) requires the investigator to define "environments".

With respect to the next to the last item above, cultivars can be evaluated for yield, quality, tolerance, usefulness as an intercrop, or a variety of other characteristics.

For intercropping investigations, the density, arrangement, and intimacy could be varied through the speu. This would be in line with the parsimonious layouts suggested by Nelder (1962), Okigbo (1978), and Mead and Riley (1981) to investigate density and spatial arrangements. The Nelder fan design and the Okigbo circle design have proven useful for studying wide ranges of such factors as plant density, plant spacing, orientation, and row spacing for a variety of crops. 


\section{$\underline{\text { Breeding Procedures }}$}

In searching for desirable genotypes, breeders commonly evaluate a quantitative trait based on a genotype mean derived from experimental units in different blocks, sites, and years. Those genotypes with the highest means are selected as parents for future crosses and/or are advanced through a breeding program and ultimately developed into cultivars. A high mean, however, does not imply low genotype by environment interaction (i.e., stability in one sense) for any specified trait. In order to obtain a genotype with the desired form of response (see Figures 1 and 2), an estimated response function for a genotype over a set of environments is characterized by a set of estimates of parameters of the response function. Using a parsimonious experiment design (PED) as described earlier, an estimated response function for yield or any other quantitative trait to changing environments may be obtained. In lieu of knowing the exact form of a response function, it may be approximated using quadratic regression with the set of estimated parameters for the intercept $(\alpha)$, slope $(\beta)$, and curvature $(\gamma)$. Genotypes may be evaluated and selected for a single component trait such as $\alpha$, which may be used to define a minimum desired level of response, or for a combination of all three components or parameters $\alpha, \beta$, and $\gamma$.

When selection is for all three parameters of the response function, not only the minimum desired value but also the shape of the response curve are considered. Additionally, selection may be practiced on the parameters for more than one quantitative trait. For example, breeders of oats (Avena sativa L.) may need to select for the desired form of response of yield to changing environments as well as a minimum groat level $(\alpha)$. In sugarcane (Saccharum officinarum L.), breeders may need to select for the desired response function for both yield of sugarcane and percentage of sucrose. This would require selection for two sets of parameters $\alpha, \beta$, and $\gamma$ to meet the desired standard.

Any manipulation for a desired response function implies the existence of genetic variability and observable phenotype differences. Oat breeders have been concerned with the genetics of stability, as defined in the literature, and have attempted to estimate heritabilities/repeatabilities of different stability parameters. Fatunla and Frey (1976) estimated the standard unit heritability of the Finlay 
and Wilkinson (1963) stability parameter for the yield of nine oat populations. They obtained values ranging from -0.35 to 0.64 , and concluded that the measure of stability was not very heritable. Later, Eagles and Frey (1977) evaluated the genetic basis of Shukla's (1972) stability parameter for the yield of grain and straw in oats. They found heritabilities from 0.78 to 0.85 , and 0.81 to 0.86 for the mean yield of grain and straw, respectively. The repeatabilities of stability ranged from 0.06 to 0.12 for grain and 0.01 to 0.30 for straw. They concluded that selection for the stability of straw yield was feasible, but not for grain yield. In cowpeas [Vigna unquiculata (L.) Walp.], Ntare and Aken'Ova (1985) computed Eberhart and Russell's (1966) stability parameter for a set of $F_{3}$ 's and their $F_{5}$ derived lines and bulks. Correlation between the stability parameters of related $F_{3}$ and $F_{5}$ lines was 0.60 , while the correlation between related $F_{3}$ and $F_{5}$ bulks was poor. Ntare and Aken'Ova (1985) did not estimate a heritability for stability, but given the genetic covariance between $F_{3}$ and $\mathrm{F}_{5}$ lines, and a correlation of 0.60 , it's clearly possible. These investigations for oats and cowpeas suggest stability has a genetic base upon which selection can be practiced.

Given this genetic base, a suitable selection technique is required. Because a desired response function may be partitioned into a set of component parts, a multiple trait selection method is needed. The three common methods include: tandem selection, independent culling levels, the selection index, or a modification/combination of these (Falconer, 1981). With tandem selection only one parameter trait is selected in a particular generation. Minimum levels of trait expression, or truncation points, are preset for each trait in each generation. In the case of $\alpha$, the minimum level would be set at $Y_{0}$ (Figure 2), and selection applied only for $\alpha$. Likewise, truncation points are set for $\beta$ and $\gamma$ and selection applied in different generations for each. Independent culling levels require the selection for all parameter traits in each generation of selection. Truncation points are set for each trait so that a group of genotypes can be identified as potential parents or breeding materials, and advanced to the next cycle of selection. The independent culling levels approach is probably the easiest and quickest way to identify suitable lines, assuming no genetic relationships among the parameter traits.

The third method, the selection index, is a more elegant procedure because it allows greater 
control of the shape of the desired response form. However, it requires the estimation of the genetic parameters (heritability and genetic correlation) associated with the three parameter traits, and the assignment of economic values to each. Each individual or family line is defined by an index value, such that

$$
\mathrm{I}_{j}=\mathrm{b}_{1} \alpha_{j}+b_{2} \beta_{j}+\mathrm{b}_{3} \gamma_{j}
$$

where

$I_{j}$ is the index value of each genotype $j$;

$b_{1}, b_{2}, b_{3}$ are the weights appropriate for each trait;

and

$\alpha_{j}, \beta_{j}$, and $\gamma_{j}$ are the measured phenotypic means for the intercept, linear, and curvilinear components of a response curve for each genotype $j$.

The estimated genetic worth, or true value $\left(\mathrm{T}_{j}\right)$ of each genotype is defined as

$$
\mathrm{T}_{j}=\mathrm{e}_{\alpha} \mathrm{G}_{\alpha j}+\mathrm{e}_{\beta} \mathrm{G}_{\beta j}+\mathrm{e}_{\gamma} \mathrm{G}_{\gamma j}
$$

where

$\mathrm{e}_{\alpha}, \mathrm{e}_{\beta}$, and $\mathrm{e}_{\gamma}$ are the economic values assigned to each of the parameter traits;

and

$\mathrm{G}_{\alpha j}, \mathrm{G}_{\beta j}$, and $\mathrm{G}_{\gamma j}$ are the unobserved genotypic values for each parameter trait $(\alpha, \beta, \gamma)$ based on a given level of gene action.

When $\mathrm{T}$ is equated to $\mathrm{I}$, the selection index equations given by Henderson (1963) are such that

$$
P \boldsymbol{b}=G_{e}
$$

where

$\boldsymbol{P}$ is a symmetric matrix of phenotypic variances (V) and covariances (C) among the parameter traits $(\alpha, \beta, \gamma)$

$\boldsymbol{b}$ is the vector of unknown weights;

$\boldsymbol{G}$ is a symmetric matrix of genetic variances $\left(\mathrm{V}_{g}\right)$ and genetic covariances $\left(\mathrm{C}_{g}\right)$ among the parameter traits;

and

$\boldsymbol{e}$ is the vector of economic values assigned to each trait.

The matrices appropriate for this example are 


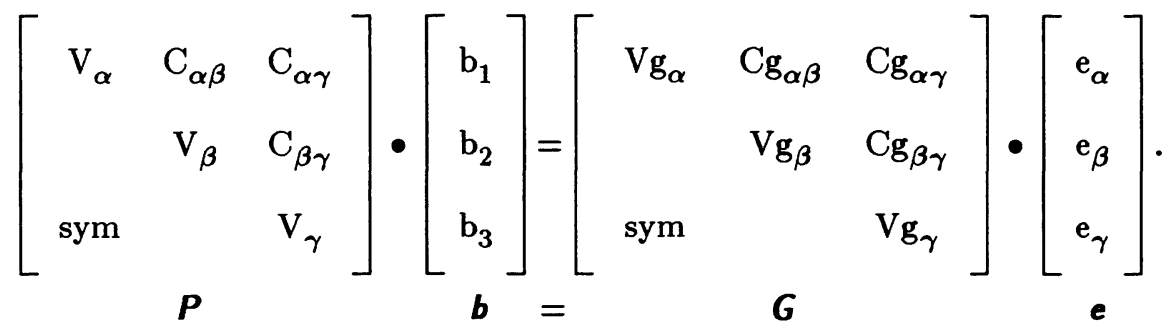

Thus $b=P^{-1} G e$, and the $b_{i}$ 's are substituted back into equation 2 and each genotype $\mathrm{j}$ is assigned an index value and ranked (Van Vleck, 1979).

The parsimonious experiment design is used to estimate the parameters of a response curve for each genotype. An augmented experiment design with the experimental units as in Figures 3 , 4 , or 5 may be used to parsimoniously screen genotypes (Federer, 1961; Federer and Raghavarao, 1975; and Federer et al., 1975). The assignment of economic weights (e values) to these traits is a difficult task, and requires a knowledge of the species. In some environments, a minimum yield is the most important aspect of the response curve, and users of the selection index may denote the economic value of $e_{\alpha}$ as 1 , while $e_{\beta}$ and $e_{\gamma}$ are set at 0 . In this situation, the breeder may need to initially employ tandem selection or independent culling levels to insure a minimum yield level at $\mathrm{Y}_{0}$ (Figure 2). In another set of circumstances, minimum yield may not be problem, but rather the inability of genotypes to improve with improving environments. This would require greater emphasis on the $\beta$ and $\gamma$ parameters, and that emphasis would be reflected in higher values of $\mathrm{e}_{\beta}$ and $\mathrm{e}_{\gamma}$ relative to the other e values. Generally, the selection index provides greater control in the selection for the shape of a desired response curve (Figure 2), allows for the correction of undesirable correlations among the parameter traits, and theoretically provides the greatest gain from selection. Restricted selection indices can also be used to preset desired gains in a given parameter trait (Baker, 1986, and included references).

Regardless of the selection technique, gain from selection is a function of the heritability, selection intensity, and the additive genetic relationships of the individuals or families in a breeding program. The choice of a breeding method can affect the estimate of an additive genetic relationship, but this is largely controlled by an organism's reproductive biology. Because the genotype must be grown across an environmental gradient, a large number of related individuals are recommended for 
accurate evaluation and selection. Breeders should attempt to minimize intra-family variation by increasing the relatedness of individuals within a family, and maximize inter-family variation to improve the probability of finding stable families. This is not to suggest that highly heterogeneous populations are unstable across environments. Clearly, the opposite is true. However, individual genotypes within a given population can vary in their forms of response to changing environments. The purpose of breeding for stability or for a desired form of response is to identify genotypes with the characteristics. These may then be combined (bulked) into heterogeneous populations as a multiline or open-pollinated cultivar. The ideal situation is found in clonally propagated crops. A family line can be derived from a single plant while variation among lines can be maximized. In selfpollinated crops, potential parents should be pure lines. If land races are included, pure line selection may be required to reduce intra-line variation. Subsequent to the selection and hybridization of parents, certain breeding procedures would be more desirable than others. Single seed descent (Brim, 1966 ) is probably the best for self-pollinated crops because families are not derived and selected until $\mathrm{F}_{7}$ and $\mathrm{F}_{8}$. At this stage the families are composed of virtually identical individuals. The mass selection method is least desirable because intra-family variation is maintained at a high level. The standard pedigree and bulk methods (Allard, 1960) would fall somewhere in between. The pedigree method is perhaps more desirable than the bulk method because individual plant selections in the early generations could be focused on parameter traits other than stability (in the sense of Lin et al., 1986). In later generations when family selection is practiced, stability response would be included as a criterion. In standard bulk breeding, intra-bulk variation is maintained at a high level until late in the program. Ntare and Aken'Ova (1985) found the use of bulks less precise for the identification of stability in early generations. Among the cross-pollinated crops nonsegregating hybrids are clearly the best, while mass-selected open-pollinated cultivars would be harder to evaluate. Generally, it can be speculated that the genotypic methods such as the half-sib, full-sib, $S_{1}$, and $S_{2}$ progeny methods are better than the phenotypic methods.

A breeding scheme could be outlined as follows:

1) redefine stability as finding a response curve with few parameters and having the desired form; 
2) evaluate potential parents in the parsimonious experiment design (PED);

3) estimate the genetic parameters of the individual parameters of the curve when using a selection index (this is not necessary for tandem selection or independent culling levels);

4) identify, select, and inter-mate parents based on a multiple trait selection criteria;

5) evaluate progeny with the desired breeding method;

6) select those families with the desired stability response,

and

7) repeat the process if recurrent selection is being practiced.

\section{Discussion}

A statistical design and breeding procedure as described above can greatly accelerate the progress of a program whose goal is to minimize risks for a grower under poor conditions and yet have a cultivar which takes advantage of increasingly more optimal conditions for increased yields. The suggested procedure is feasible and efficient from a cost and other resource viewpoint. It makes possible what is impossible under some present thinking and presently used procedures and is an extension of other procedures now in use.

The area selected for the experiment using a PED should be such that levels of factors are added rather than subtracted. Thus a nonfertile, arid, insect-free, and disease-free area would be ideal for a PED. Such areas are found in many parts of the world. Changes in length of drought periods could easily be made when selecting for sorghum-like drought period tolerance for a crop.

To vary insect and disease populations within one speu may require creativity on the part of the investigator. If diseases and insects spread uniformly throughout the season, a disease and/or insect source could be put at one end of the speus in Figure 3. Plants closest to the source would be most heavily infected while those most distant would be least infected. If this cannot be done then the level of disease and/or insects may have to be a whole plot treatment, perhaps even in different fields.

As noted above, many types of characteristics could be used. For example, lodging, fiber content, protein level, tolerance, etc. could be used as a basis for comparing cultivars using the statistical design described above. Such a goal suggests use of a selection index. Farming systems involving levels of factors could be evaluated in intercropping research in much the same manner. 
It has been suggested that a response curve with a set of parameters be used. As an alternative, an experimenter may wish simply to find the area under the response curve obtained for an experimental unit. These areas would then serve as the data points for a statistical analysis. Also, the minimum and maximum values obtained, as well as their differences, may be used as the data values in lieu of fitting a quadratic or other regression equation. Computer programs may be written to obtain these statistics from the original data if desired.

A number of abiotic stress investigations have successfully determined genotypic responses across an imposed environmental gradient. In rice (Oryiza sativa L.), IRRI (1979, 1980, and 1981) screened 750 genotypes for cold tolerance using an experimental unit of the form in Figure 3. Cold water $\left(17^{\circ} \mathrm{C}\right)$ was pumped into the field and temperatures slowly increased to ambient $\left(27^{\circ} \mathrm{C}\right)$ as water flowed across the paddy. Genotypes with the ability to tolerate cold were easily distinguished by plant height, tiller number, spikelet fertility, and other morphological traits. In Nigeria, upland rice genotypes were tested for drought tolerance using this same basic design (B. N. Okigbo, 1978, personal communication). In drought research, the line source sprinkler system designed by Hanks et al. (1976) is ideally suited for the selection and breeding procedure presented above. In California, Epstein and collaborators (Epstein and Norlyn, 1977; Kingsbury and Epstein, 1984; Kelly et al., 1979; Norlyn and Epstein, 1982; and Richards et al., 1982) have evaluated the salt tolerance of small grains (barley, triticale, and wheat) and tomatoes (Lycopersicon esculentum L.). Using sites with natural salinity gradients, as in Figure 3, genotypes were evaluated to determine their adaptability to stress. Genotypes were compared and judged by response curves similar to Figures 1 and 2 (Jones and Qualset, 1984). Salt tolerance of barley (Hordeum vulgare L.) was also evaluated by irrigating genotypes with proportions of sea and fresh water. Genotypes were evaluated for yield and biomass.

In most of these examples, estimates of the response curve parameters were not computed. However, each investigator was keenly aware of the response function of each genotype, or the genotype by environment interaction. From these investigations, it appears that a form of the parsimonious design is an integral part of most abiotic stress research. We urge that a response curve methodology be incorporated into these evaluations. Selection could then be applied not only for a threshold level, but also for a particular form of desired response. 


\section{$\underline{\text { Conclusion }}$}

The present concept of stability as described in the literature should perhaps be discarded. It would appear inappropriate to denote the cultivars which gave responses in Figure 2 as "stable". A name for these responses was not found except to denote them as desired responses, curves, or functions. The concept of stability as found in the literature does not appear useful in a breeding program for maximizing returns. Cultivars meeting the present criteria of low variance and low linear slope would not meet the criteria in Figure 2 and the criterion suggested by Verma et al. (1978) and Pooni and Jinks (1980). In fact, the most "stable" genotype is one which yields zero in every environment!

This parsimonious design has the advantage of flexibility and is an inexpensive method for determining a response to changing environments, selecting parents, and evaluating progeny. It further describes a genotype's response not just as a single value, but rather as a set of component traits based on fitting a regression equation to the data. These component traits can then be selected and manipulated to meet the requirements of the environment and cropping system using a selection index approach. 


\section{$\underline{\text { Literature Cited }}$}

1. Allard, R.W.(1960). Principles of Plant Breeding. John Wiley \& Sons, Inc., New York, 485 pp.

2. Baker, R.J.(1986). Selection Indices in Plant Breeding. CRC Press, Inc., Boca Raton, FL, 218 pp.

3. Brim, C.A.(1966). A modified pedigree method of selection in soybeans. Crop Sci. 6: 220.

4. Eagles, H.A. and K.J. Frey (1977). Repeatability of the stability-variance parameter in oats. Crop Sci. 17: 253-256.

5. Eberhart, S.A. and W.A. Russell.(1966). Stability parameters for comparing varieties. Crop Sci. 6: $36-40$.

6. Epstein, E. and J.D. Norlyn (1977). Seawater-based crop production: A feasibility study. Science 197: 249-251.

7. Falconer, D.S.(1981). Introduction to Quantitative Genetics (2nd ed.). Longmans Group Ltd., London, $340 \mathrm{pp}$.

8. Fatunla, T. and K.J. Frey (1976). Repeatability of regression stability indexes for grain yield of oats (Avena sativa L.). Euphytica 25: 21-28.

9. Federer, W.T.(1961). Augmented designs with one-way elimination of heterogeneity. Biometrics 17: 447-473.

10. Federer, W.T.(1993). Statistical Design and Analyses for Intercropping Experiments: Two Crops. Springer-Verlag, New York (in press).

11. Federer, W.T., R.C. Nair, and D. Raghavarao (1975). Some augmented row-column designs. Biometrics 31: 361-374.

12. Federer, W.T. and D. Raghavarao (1975). On augmented designs. Biometrics 31:29-35.

13. Finlay, K.W. and G.N. Wilkinson (1963). The analysis of adaptation in a plant-breeding programme. Aust. J. Agric. Res. 14:742-754.

14. Francis, C. A.(1981). Development of plant genotypes for multiple cropping systems. In Plant Breeding II, K.J. Frey (ed.). Iowa State Univ. Press, Ames, Iowa, pp. 179-232.

15. Hanks, R.J., J. Keller, V.P. Rasmussen, and G.D. Wilson (1976). Line source-sprinkler for continuous variable irrigation crop production studies. Soil Sci. Soc. Am. J. 40: 426-429. 
16. Henderson, C.R.(1963). Selection index and expected genetic advance. In Statistical Genetics and Plant Breeding, W.D. Hanson and F. Robinson (eds.). National Academy of Sciences, Washington, D.C., pp. 141-163. NAS-NRC 982.

17. IRRI (1979). Annual Report for 1978, The International Rice Research Institute, Los Baños, Laguna, Philippines, pp. 138-141.

18. IRRI (1980). Annual Report for 1979, The International Rice Research Institute, Los Baños, Laguna, Philippines, pp. 138-142.

19. IRRI (1981). Annual Report for 1980, The International Rice Research Institute, Los Baños, Laguna, Philippines, pp. 128-133.

20. Jones, R.A. and C.O. Qualset (1984). Breeding crops for environmental stress tolerance. In Applications of Genetic Engineering to Crop Improvement, G.B. Collins and J.G. Petolino (eds.). Martinus Nijhoff/Dr. W. Junk Publ., Boston, pp. 305-341.

21. Kelly, D.B., J.D. Norlyn, and E. Epstein (1979). Salt tolerant crops and saline water resources for arid lands. In Proc. of the International Arid Lands Conference on Plant Resources, J.R. Goodin and D.K. Northlington (eds.). Texas Tech. Univ. Press, Lubbock, pp. 326-334.

22. Kingsbury, R.W. and E. Epstein (1984). Selection for salt-resistant spring wheat. Crop Sci. 24: $310-315$.

23. Lin, C.S., M.R. Binns, and L.P. Lefkovitch (1986). Stability analysis: Where do we stand? Crop Sci. 26: 894-900.

24. Mead, R. and J. Riley (1981). A review of statistical ideas relevant to intercropping research. J. Roy. Statist. Soc., Ser. A. 144: 462-509.

25. Nelder, J.A.(1962). New kinds of systematic designs for spacing experiments. Biometrics 18: 283-307.

26. Norlyn, J.D. and E. Epstein (1982). Barley production: Irrigation with seawater on coastal soil. In Biosaline Research: A Look to the Future, Proc. of the 2nd International Workshop on Biosaline Research, 1980, A. San Petro (ed.). Environmental Science Research Vol. 23, Plenum Press, New York, pp. 525-529. 
27. Ntare, B.R. and M. Aken'Ova (1985). Yield stability in segregating populations of cowpea. Crop Sci. 25: 208-211.

28. Okigbo, B.N.(1978). Personal communication, IITA, Ibadan, Nigeria.

29. Pooni and Jinks (1980).

30. Richards, R.A., C.W. Dennat, C.W. Schaller, C.O. Qualset, and E. Epstein (1982). Selection for yield in cereals for salt-affected croplands. In Biosaline Research: A Look to the Future, Proc. of the 2nd International Workshop on Biosaline Research, 1980, A. San Petro (ed.). Environmental Science Research Vol. 23, Plenum Press, New York, pp. 535-537.

31. Shulka, G.K. (1972). Some statistical aspects of partitioning genotype-environmental components of variability. Heredity 29: 237-245.

32. Van Vleck, L.D. (1979). Notes on the theory and application of selection principles for the genetic improvement of animals. Unpublished Technical Report, Dept. of Animal Science, Cornell University, Ithaca, NY, 273 pp.

33. Verma, N.M., G.S. Chahal, and B.R. Murty (1978). Limitations of conventional regression analysis: A proposed modification. Theor. and Appl. Genet. 53: 89-91. 